Acta Crystallographica Section B

Structural

Science

ISSN 0108-7681

Editor: Carolyn P. Brock

The role of second coordination-sphere interactions in incommensurately modulated structures, using $\beta-\mathrm{K}_{5} \mathrm{Yb}\left(\mathrm{MoO}_{4}\right)_{4}$ as an example

Alla Arakcheeva, Gervais Chapuis, Vâclav Petricek and Vladimir Morozov

Copyright $($ International Union of Crystallography

Author(s) of this paper may load this reprint on their own web site provided that this cover page is retained. Republication of this article or its storage in electronic databases or the like is not permitted without prior permission in writing from the IUCr. 
Acta Crystallographica Section B

Structural

Science

ISSN 0108-7681

\section{Alla Arakcheeva, ${ }^{a}$ Gervais Chapuis, $^{a *}$ Vâclav Petricek ${ }^{b}$ and Vladimir Morozov ${ }^{c}$}

\begin{abstract}
a'Ecole Polytechnique Fédérale de Lausanne, Laboratoire de cristallographie, BSP, CH-1015 Lausanne, Switzerland, ${ }^{\mathbf{b}}$ Institute of Physics, Academy of Sciences of the Czech Republic, $\mathrm{Na}$ Slovance 2, 18221 Praha 8, Czech Republic, and ${ }^{\mathrm{c}}$ Department of Chemistry, Moscow State University, 119899 Moscow, Russia
\end{abstract}

Correspondence e-mail gervais.chapuis@epfl.ch

\section{The role of second coordination-sphere interactions in incommensurately modulated structures, using $\beta$ - $\mathrm{K}_{5} \mathrm{Yb}\left(\mathrm{MoO}_{4}\right)_{4}$ as an example}

The incommensurate palmierite-like structure of $\beta$ $\mathrm{K}_{5} \mathrm{Yb}\left(\mathrm{MoO}_{4}\right)_{4}$, potassium ytterbium tetramolydate, has been refined in the $(3+1)$-dimensional monoclinic superspace

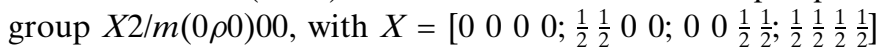
and the unit-cell parameters $a=10.4054$ (16), $b=6.1157$ (12), $c=19.7751$ (18) ^, $\beta=136.625(10)^{\circ} ; \mathbf{q}=0.6354$ (30)b*. The occupations of the $\mathrm{K}$ and $\mathrm{Yb}$ atomic positions are described by crenel functions. The structure model reveals a balanced interaction between the atoms of the first and second coordination spheres. It is shown that the third coordination sphere should not be neglected in studies of modulated structures. The ordering of the $\mathrm{K}$ and $\mathrm{Yb}$ atoms appears to be the driving force for the modulation of all the other atoms.

\section{Introduction}

The origin of the incommensurability in crystals was at the center of many theoretical models, which have been extensively discussed in the literature. In particular, ANNNI, DIFFOUR and other models (see, for example, Selke \& Fischer, 1979; Bak, 1982; Janssen \& Tjon, 1981) are based on competing interactions between nearest-neighbor and nextnearest-neighbor particles. From the theoretical considerations of Parlinski \& Chapuis (1993) it was also shown that the role of atomic interactions not only of the first but also of the second coordination sphere (cation-cation for the anioncontaining compounds) was fundamental for the formation of incommensurably modulated structures. The study of incommensurate structures as a probe to reveal atomic interactions in crystals has already been discussed with the examples of $\mathrm{Na}_{2} \mathrm{CO}_{3}$ and $\mathrm{K}_{3} \operatorname{In}\left(\mathrm{PO}_{4}\right)_{2}$ (Chapuis \& Arakcheeva, 2004; Arakcheeva et al., 2003). In both crystals, the cation-cation interactions were identified as the driving forces and primary parameters of the modulations in the corresponding structures. Another example of cation-cation interactions was described by Dusek et al. (2002) for the monophosphate tungsten bronze $\mathrm{K}_{1.33} \mathrm{P}_{4} \mathrm{~W}_{8} \mathrm{O}_{32}$, where the phase transition mechanism was associated with the release of internal strain between the $\mathrm{K}$ atoms and the surrounding $\mathrm{PO}_{4}$ groups.

In the present paper we pursue our main goal of identifying the fundamental interactions in incommensurate structures with the investigation of $\beta-\mathrm{K}_{5} \mathrm{Yb}\left(\mathrm{MoO}_{4}\right)_{4}$. Three modifications of the complex molybdenum oxide $\mathrm{K}_{5} \mathrm{Yb}\left(\mathrm{MoO}_{4}\right)_{4}$ belonging to the palmierite $\left[\mathrm{K}_{2} \mathrm{~Pb}\left(\mathrm{SO}_{4}\right)\right]$ structure type were recently identified by Morozov et al. (2003):

(i) the high-temperature phase $\alpha$, space group $R \overline{3} m, a=$ 6.0372 (1), $c=20.4045$ (2) Aं;
Received 14 April 2005

Accepted 31 May 2005 
(ii) the low-temperature phase $\gamma$, space group $C 2 / c, a=$ 14.8236 (1), $b=12.1293$ (1), $c=10.5151$ (1) $\AA$, $\gamma=114.559$ (1) ${ }^{\circ}$;

(iii) an intermediate-temperature phase $\beta$, which is incommensurate according to electron diffraction investigations.

The palmierite structure type is well known and the rhombohedral $\alpha-\mathrm{K}_{5} \mathrm{Yb}\left(\mathrm{MoO}_{4}\right)_{4}$ modification is as shown in Fig. 1. The structure is built up from two alternating layers along the trigonal c axis. The first layer consists of $\mathrm{MoO}_{4}$ tetrahedra and $M_{6}$ octahedra $(M=\mathrm{K}, \mathrm{Yb})$, whereas the second layer consists of $\mathrm{KO}_{10}$ polyhedra. In this article, however, we would like to single out another building unit which will play an important role in the description of the incommensurate structure, namely layer $\mathrm{L}$ as indicated in Fig. 1. This layer (Fig. 1b) is normal to the trigonal c axis and consists of $\mathrm{MoO}_{4}$ tetrahedra, $\mathrm{MO}_{6}$ octahedra and $\mathrm{K}$ atoms.
The whole structure thus consists of three identical layers related by the translation vectors of the $R$ lattice. In the same publication (Morozov et al., 2003), the crystal structures of phases $\alpha$ and $\gamma$ were also refined. According to this study, the $M$ position of the $\gamma$ modification (Fig. 1) was statistically occupied by $\left(\mathrm{K}_{0.5} \mathrm{Yb}_{0.5}\right)$, whereas ordering of $\mathrm{K}$ and $\mathrm{Yb}$ atoms was observed in the $\gamma$ phase. A model based on a combination of $\alpha$ - and $\gamma$-structural entities was proposed for the incommensurate modification $\beta$.

The purpose of the present publication is the determination and refinement of the incommensurately modulated $\beta$ phase. In addition, we analysed the atomic interactions resulting from the first (cation-oxygen) and second (cation-cation) coordination spheres in an attempt to reveal the complementary character of the two types of interactions.

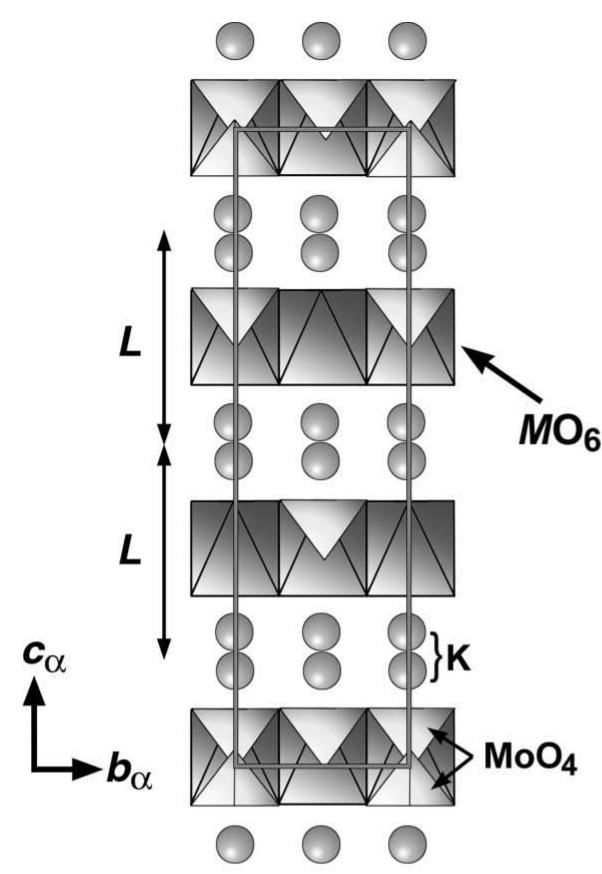

(a)
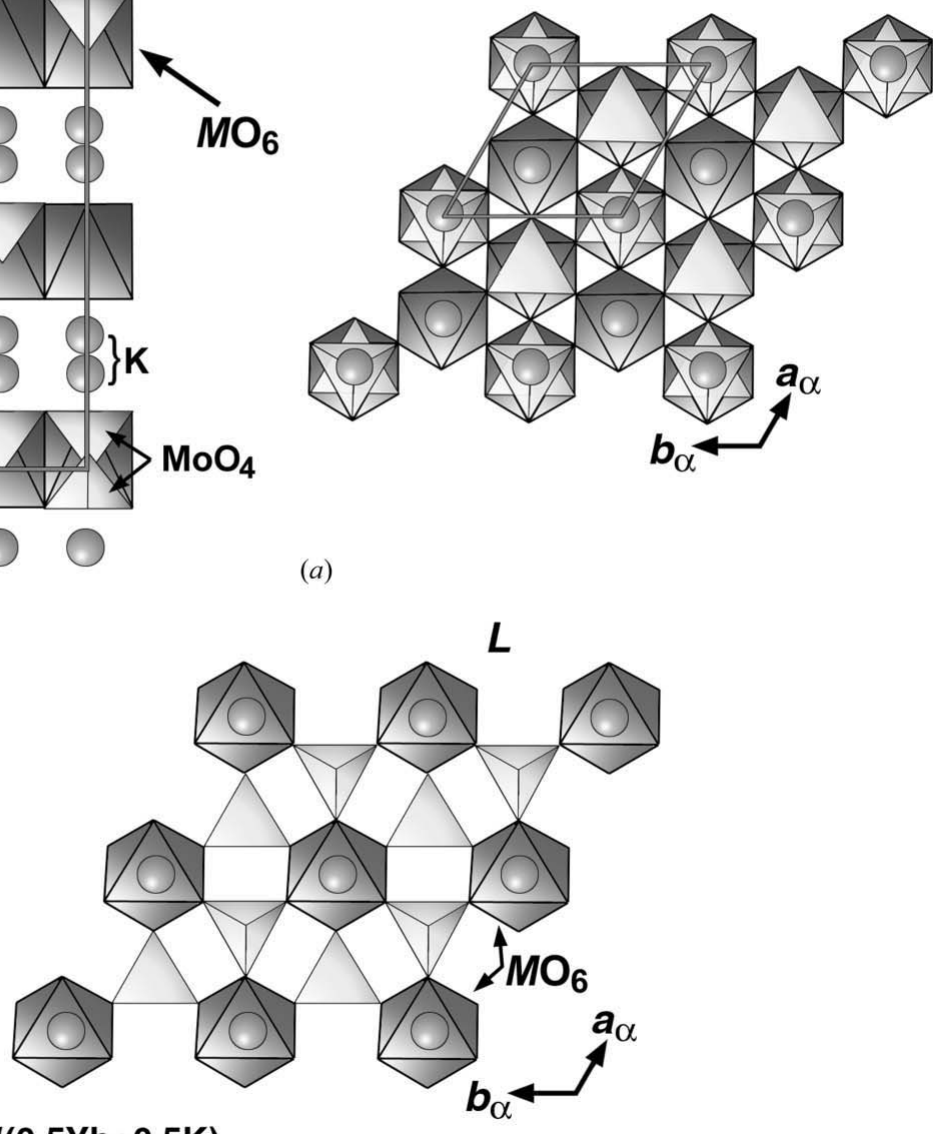

$M(0.5 \mathrm{Yb}+0.5 \mathrm{~K})$

(b)

Figure 1

The palmierite structure type, space group $R \overline{3} m$. (a) Two projections of the structure. $L$ layers are indicated. (b) A single $L$ layer consisting of $\left[\mathrm{MoO}_{4}\right]$ and $\left[\mathrm{MO}_{6}\right]$ polyhedra, and $\mathrm{K}$ atoms which are located on both sides of the $\left[\mathrm{MO}_{6}\right]$ octahedra along $c$.
2. Experimental study of the incommensurate $\beta$ $\mathrm{K}_{5} \mathrm{Yb}\left(\mathrm{MoO}_{4}\right)_{4}$ structure

\subsection{Preparation}

Details of the preparation of $\mathrm{K}_{5} \mathrm{Yb}\left(\mathrm{MoO}_{4}\right)_{4}$ by a conventional ceramic technique, as well as the conditions for the $\alpha, \beta$ and $\gamma$ transformations and phase identification by electron- and X-ray powder diffraction techniques have previously been described by Morozov et al. (2003). The low-temperature modification $\gamma$ was obtained at $893 \pm 10 \mathrm{~K}$. Annealing of this phase at $960 \pm$ $10 \mathrm{~K}$ (close to the melting point) for $3 \mathrm{~h}$ followed by quick quenching by liquid nitrogen freezes the high-temperature $\alpha$ modification. Slow cooling from $960 \mathrm{~K}$ to room temperature induces the formation of the $\beta$ modification.

Single crystals of $\beta$ $\mathrm{K}_{5} \mathrm{Yb}\left(\mathrm{MoO}_{4}\right)_{4}$ were grown by spontaneous crystallization of the melt. The temperature was automatically controlled with an accuracy of $\pm 0.5 \mathrm{~K}$. The cooling rate from 973 to $673 \mathrm{~K}$ was 3$5 \mathrm{~K} \mathrm{~h}^{-1}$, which was followed by cooling to room temperature in the cooling furnace regime.

\subsection{X-ray experiment and results of structure refinement}

The experimental details are summarized in Table 1. All 


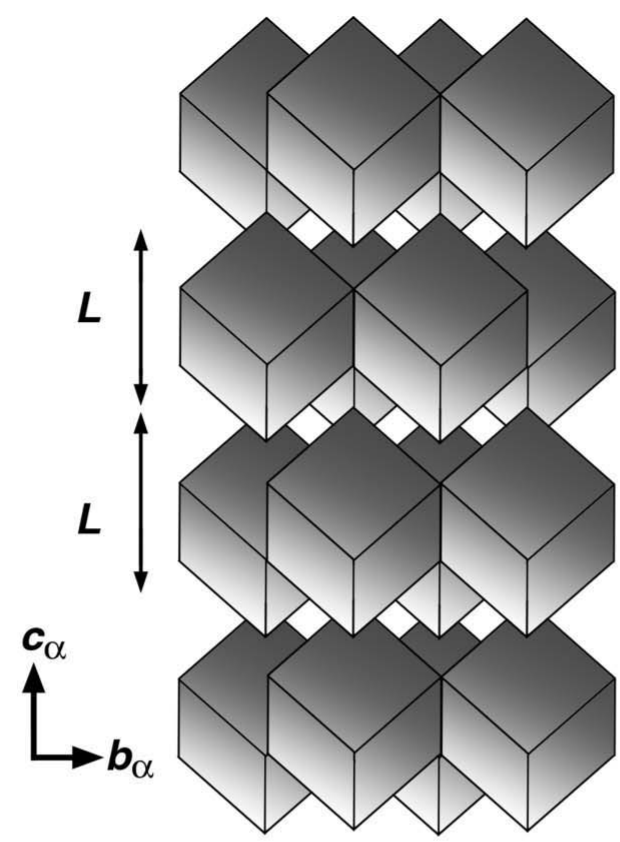

(a)

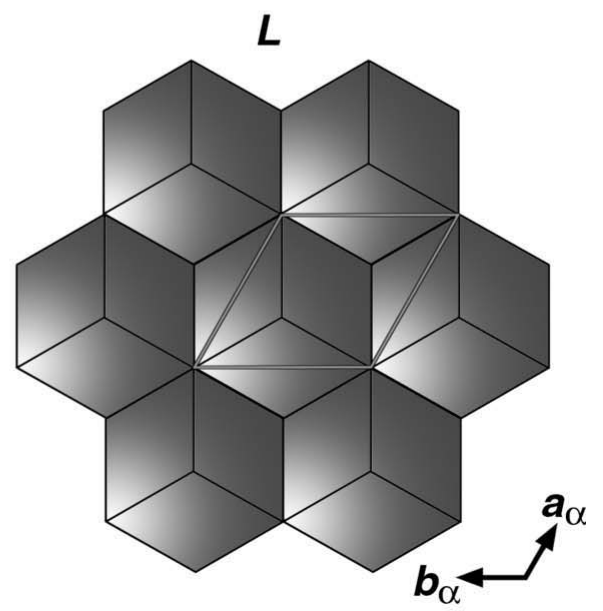

(b)

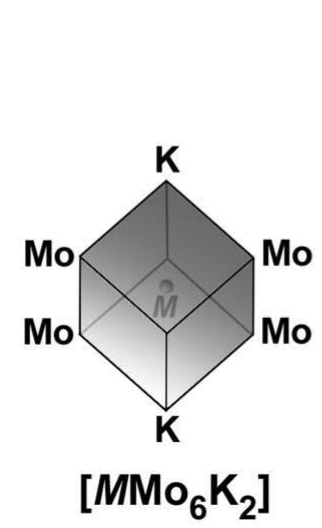

Mo

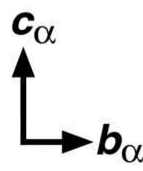

Figure 2

The palmierite structure type as a combination of $\left[M \mathrm{Mo}_{6} \mathrm{~K}_{2}\right]$ cubic clusters. The projections in $(a)$ and $(b)$ $(L)$ are analogous to Fig. 1. The structure of a single cluster is also represented.

reflections within the sphere limited by $\theta=34.66^{\circ}$ including satellites up to third order were measured. The refinement of the unit-cell parameters, including the modulation vector $\mathbf{q}$, was performed using the CrysAlis software (Oxford Diffraction Ltd, 2001) and the program NADA (Schönleber et al., 2001 ) in the conventional monoclinic setting and with $\mathbf{q}=\left[0 \mathbf{a}^{*}\right.$ $\left.+\beta \mathbf{b}^{*}+0 \mathbf{c}^{*}\right]$. The unit-cell parameters of the $\alpha, \beta$ and $\gamma$ modifications are related by the following expressions: $\mathbf{a}_{\beta}=-\mathbf{c}_{\gamma}=\left(2 \mathbf{a}_{\alpha}+\mathbf{b}_{\alpha}\right) ; \quad \mathbf{b}_{\beta}=0.5 \mathbf{b}_{\gamma}=\mathbf{b}_{\alpha} ;$ $\mathbf{c}_{\beta}=\left(\mathbf{a}_{\gamma}+2 \mathbf{c}_{\gamma}\right)=-4 / 3\left(2 \mathbf{a}_{\alpha}+\mathbf{b}_{\alpha}\right)+2 / 3 \mathbf{c}_{\alpha}$. The non-primitive centring $X$ in the $(3+1)$-dimensional superspace (Table 1) corresponds to the three-dimensional average unit cell with $\mathbf{c}_{\mathrm{av}}=0.5 \mathbf{c}_{\beta}$ and the space group $C 2 / \mathrm{m}$.

The JANA2000 system of programs (Petricek et al., 2000) was used for structure refinement and analysis. The starting models of the cations in the average structure were calculated from the rhombohedral $\alpha$ phase (Morozov et al., 2003). This starting model can be represented by $L$ layers of edge-sharing cubic clusters with the composition $\left[\mathrm{MMo}_{6} \mathrm{~K}_{2}\right] \quad$ (Fig. 2), which completely characterizes the palmierite (cationic) structure. The translation vector $\mathbf{c}_{\alpha}$ is related to the body diagonals of the cubes located at the centre of the $R$ lattice, while $\mathbf{a}_{\alpha}$ is oriented along the face diagonal of the cube. The starting model was refined for the average structure in the monoclinic unit cell by using only the main reflections. The $\mathrm{O}$ atoms could not be unambigously localized in the refined structure. By including first- and second-order satellites, it was possible to distinguish between the $\mathrm{Yb}$ and K1 atoms occupying the $M$ position and their occupation could be reasonably described by two complementary crenel functions. The $\mathrm{O}$ atoms were located from a difference Fourier synthesis in the vicinity of Mo. The $\left[\mathrm{MoO}_{4}\right]$ group was further refined as a rigid unit. The K-atom position of the $\alpha$ phase (Figs. 1 and 2) corresponds to $\mathrm{K} 2$ in the present structure. The position of $\mathrm{K} 2$ and the rigid-body groups $\left(\mathrm{MoO}_{4}\right)$ exhibit a clear discontinuity and their positional modulations can be divided into two mutually related $t$ regions, which are best represented by crenel functions. The final coordinates, parameters of the relevant crenel functions and equivalent isotropic displacement parameters have been deposited. ${ }^{\mathbf{1}}$ Two positions of the $\left[\mathrm{MoO}_{4}\right]$ rigid unit $[(a)$ and $(b)$ in the tables] are tilted and shifted, and the corresponding parameters are listed in Table 2.

A selection of relevant interatomic distances and angles are presented in Table 3 (a complete list of distances is available in the supplementary materials). The interatomic distances in the

\footnotetext{
${ }^{1}$ Supplementary data for this paper, including the $\mathrm{Yb}, \mathrm{K} 1, \mathrm{~K} 2 a$ and $\mathrm{K} 2 b$ Fourier components of the positional amplitudes, amplitudes of the displacive modulation functions, amplitudes for the rotation and translation modulations of the $(a)$ and $(b)\left[\mathrm{MoO}_{4}\right]$ rigid unit positions, displacement parameters and ADP modulation functions for all atoms, are available from the IUCr electronic archives (Reference: SN5021). Services for accessing these data are described at the back of the journal.
} 
research papers

Table 1

Experimental data.

\begin{tabular}{|c|c|}
\hline \multicolumn{2}{|l|}{ Crystal data } \\
\hline Chemical formula & $\mathrm{K}_{5} \mathrm{Yb}\left(\mathrm{MoO}_{4}\right)_{4}$ \\
\hline$M_{r}$ & 1008.3 \\
\hline System, superspace group & Monoclinic, $X 2 / m(0 \beta 0) 00$ \\
\hline Non-primitive translations & {$\left[\frac{1}{2} \frac{1}{2} 00 ; 0 ; 00 \frac{1}{2} \frac{1}{2} ; \frac{1}{2} \frac{1}{2} \frac{1}{2} \frac{1}{2}\right]$} \\
\hline$a, b, c(\AA)$ & $10.4054(16), 6.1157(12), 19.7751(18)$ \\
\hline$\beta\left({ }^{\circ}\right)$ & $136.625(10)$ \\
\hline$V\left(\AA^{3}\right)$ & $864.2(3)$ \\
\hline$Z$ & 2 \\
\hline$D_{x}\left(\mathrm{Mg} \mathrm{m}^{-3}\right)$ & $3.873(1)$ \\
\hline Modulation vector & $\mathbf{q}=0.6354(30) \mathbf{b}^{*}$ \\
\hline Radiation type & Мo $K \alpha$ \\
\hline $\begin{array}{l}\text { No. of reflections for } \\
\text { cell parameters }\end{array}$ & 5412 \\
\hline$\theta$ range $\left({ }^{\circ}\right)$ & $5.3-37.7$ \\
\hline$\mu\left(\mathrm{mm}^{-1}\right)$ & 9.46 \\
\hline Temperature (K) & 293 \\
\hline Crystal form, colour & Isomorphic, colourless \\
\hline Crystal size (mm) & $0.14 \times 0.13 \times 0.12$ \\
\hline \multicolumn{2}{|l|}{ Data collection } \\
\hline Diffractometer & KM4 \\
\hline $\begin{array}{l}\text { Data collection method CCD } \\
\text { detector }\end{array}$ & KM4CCD/Sapphire \\
\hline Absorption correction & Analytical \\
\hline$T_{\min }$ & 0.159 \\
\hline$T_{\max }$ & 0.200 \\
\hline $\begin{array}{l}\text { No. of measured, independent } \\
\text { and observed reflections }\end{array}$ & $67857,6142,3412$ \\
\hline $\begin{array}{l}\text { Criterion for observed } \\
\text { reflections }\end{array}$ & $I>3 \sigma(I)$ \\
\hline$R_{\text {int }}$ & 0.12 \\
\hline$\theta_{\max }\left({ }^{\circ}\right)$ & 69.3 \\
\hline Range of $h, k, l$ & $-12 \Rightarrow h \Rightarrow 12$ \\
\hline & $-10 \Rightarrow k \Rightarrow 10$ \\
\hline & $-35 \Rightarrow l \Rightarrow 35$ \\
\hline \multicolumn{2}{|l|}{ Refinement } \\
\hline Refinement on & $F$ \\
\hline$R\left[F^{2}>2 \sigma\left(F^{2}\right)\right], w R\left(F^{2}\right), S$ & $0.077,0.085,2.89$ \\
\hline No. of reflections & 3412 \\
\hline No. of parameters & 94 \\
\hline Weighting scheme & $w=1 /\left[\sigma^{2}(F)+0.0001 F^{2}\right]$ \\
\hline$(\Delta / \sigma)_{\max }$ & 0.001 \\
\hline$\Delta \rho_{\max }, \Delta \rho_{\min }\left(\mathrm{e} \AA^{-3}\right)$ & $5.24,-5.20$ \\
\hline Extinction method & $\begin{array}{l}\text { B-C type } 1 \text { Lorentzian isotropic } \\
\text { (Becker \& Coppens, 1974) }\end{array}$ \\
\hline Extinction coefficient & $0.021(6)$ \\
\hline
\end{tabular}

Computer programs used: CrysAlis (Oxford Diffraction Ltd, 2001).

first and second coordination spheres of $\mathrm{Yb}$ and $\mathrm{K} 1$ are represented as a function of the internal coordinate $t$ in Fig. 3 .

The length of the $\mathrm{Yb}$ crenel function $[0.512(2)]$ is slightly larger than the length of the K1 crenel function [0.488 (2)], while the stoichiometry of the compound, as confirmed by chemical analyses (Morozov et al., 2003), requires equal amounts of $\mathrm{Yb}$ and $\mathrm{K} 1$ atoms. In order to explain this asymmetry, we tested both a model with a modulation of the $\mathrm{Yb}$ occupation and a model with an additional crenel function for a mixed $\left(\mathrm{K}_{0.5} \mathrm{Yb}_{0.5}\right)$ composition. Both models led to unrealistic ADP parameters for the $\mathrm{Yb}$ and $\left(\mathrm{K}_{0.5} \mathrm{Yb}_{0.5}\right)$ positions. Indeed, no essential modulations of the ADP parameters (see supplemental materials) were observed for the $\mathrm{Yb}$ position in our final model. Therefore, it is likely that over a short range along $t\left(\Delta t_{\mathrm{Yb}}=0.0248\right)$ the modulation corresponds to a mixed
Table 2

Basic rotation and translation displacements for two ( $a$ and $b$ ) positions of the $\left[\mathrm{MoO}_{4}\right]$ rigid unit in $\beta-\mathrm{K}_{5} \mathrm{Yb}\left(\mathrm{MoO}_{4}\right)_{4}$.

\begin{tabular}{llllllll}
\hline & \multicolumn{3}{l}{ Rotation components $\left({ }^{\circ}\right)$} & & \multicolumn{4}{l}{ Translation components } \\
\cline { 2 - 3 } \cline { 6 - 8 } Position & $r_{x}$ & $r_{y}$ & $r_{z}$ & & $t_{x}$ & $t_{y}$ & $t_{z}$ \\
\hline (a) & 0 & 0 & 0 & & $-0.00030(11)$ & 0 & $-0.00013(6)$ \\
(b) & 0 & $35.8(5)$ & 180 & & $-0.0608(5)$ & 0 & $-0.0275(3)$ \\
\hline
\end{tabular}

Table 3

Selected cation-oxygen distances $(\AA)$ and angles $\left({ }^{\circ}\right)$ in the $\left[\mathrm{MoO}_{4}\right]$ tetrahedra in $\beta-\mathrm{K}_{5} \mathrm{Yb}\left(\mathrm{MoO}_{4}\right)_{4}$

\begin{tabular}{|c|c|c|c|}
\hline & Average & Minimal & Maximal \\
\hline $\mathrm{Yb}-\mathrm{O} 1 a$ & $2.293(14)$ & $2.168(14)$ & $2.686(14)$ \\
\hline $\mathrm{Yb}-\mathrm{O} 2 a$ & $2.31(3)$ & $2.21(3)$ & $2.45(3)$ \\
\hline $\mathrm{Yb}-\mathrm{O} 2 b$ & $2.26(19)$ & $2.2(3)$ & $2.36(13)$ \\
\hline $\mathrm{K} 1-\mathrm{O} 1 a$ & $2.990(17)$ & $2.461(18)$ & $3.13(2)$ \\
\hline $\mathrm{K} 1-\mathrm{O} 2 a$ & $2.84(4)$ & $2.55(3)$ & $3.10(7)$ \\
\hline $\mathrm{K} 1-\mathrm{O} 1 b$ & 2.67 (3) & $2.48(3)$ & $2.96(3)$ \\
\hline $\mathrm{K} 1-\mathrm{O} 3 a$ & $2.97(3)$ & $2.90(3)$ & 3.17 (3) \\
\hline $\mathrm{K} 1-\mathrm{O} 3 a$ & 3.45 (4) & $2.80(8)$ & 3.88 (4) \\
\hline $\mathrm{K} 2 a-\mathrm{O} 1 a$ & $2.89(3)$ & $2.53(3)$ & 3.19 (2) \\
\hline $\mathrm{K} 2 a-\mathrm{O} 1 a$ & 3.27 (4) & $2.92(4)$ & 3.61 (4) \\
\hline $\mathrm{K} 2 a-\mathrm{O} 1 a$ & 3.15 (3) & $2.83(3)$ & $3.41(3)$ \\
\hline $\mathrm{K} 2 a-\mathrm{O} 2 a$ & $2.839(15)$ & $2.539(18)$ & $3.136(15)$ \\
\hline $\mathrm{K} 2 a-\mathrm{O} 2 a$ & $3.294(15)$ & $2.843(18)$ & $3.682(17)$ \\
\hline $\mathrm{K} 2 a-\mathrm{O} 3 a$ & $2.60(3)$ & $2.49(4)$ & $2.75(3)$ \\
\hline $\mathrm{K} 2 a-\mathrm{O} 1 b$ & $3.30(6)$ & $2.61(5)$ & $3.98(5)$ \\
\hline $\mathrm{K} 2 a-\mathrm{O} 1 b$ & $2.86(6)$ & $2.53(6)$ & 3.27 (4) \\
\hline $\mathrm{K} 2 a-\mathrm{O} 3 b$ & $2.61(18)$ & $2.6(3)$ & $2.64(13)$ \\
\hline $\mathrm{K} 2 a-\mathrm{O} 3 b$ & $3.32(4)$ & $2.63(4)$ & $3.97(3)$ \\
\hline $\mathrm{K} 2 b-\mathrm{O} 1 a$ & $2.91(7)$ & $2.84(9)$ & 3.09 (6) \\
\hline $\mathrm{K} 2 b-\mathrm{O} 1 a$ & $3.13(8)$ & $3.05(5)$ & $3.36(6)$ \\
\hline $\mathrm{K} 2 b-\mathrm{O} 2 a$ & $2.78(6)$ & $2.76(9)$ & $2.82(4)$ \\
\hline $\mathrm{K} 2 b-\mathrm{O} 2 a$ & $2.88(2)$ & $2.81(2)$ & $2.924(18)$ \\
\hline $\mathrm{K} 2 b-\mathrm{O} 1 b$ & 3.29 (13) & $2.64(9)$ & $3.54(10)$ \\
\hline $\mathrm{K} 2 b-\mathrm{O} 2 b$ & $2.96(8)$ & $2.82(6)$ & 3.04 (12) \\
\hline \multicolumn{4}{|l|}{ Mo $a$ tetrahedron } \\
\hline $\mathrm{Mo}-\mathrm{O} 1 \times 2$ & $1.78(2)$ & $1.73(3)$ & $1.83(3)$ \\
\hline $\mathrm{Mo}-\mathrm{O} 2$ & $1.77(3)$ & $1.74(3)$ & $1.87(4)$ \\
\hline $\mathrm{Mo}-\mathrm{O} 3$ & $1.72(2)$ & $1.684(19)$ & $1.77(7)$ \\
\hline $\mathrm{O} 1-\mathrm{Mo}-\mathrm{O} 2$ & $110.4(12)$ & $108.2(14)$ & $113.3(13)$ \\
\hline $\mathrm{O} 1-\mathrm{Mo} a-\mathrm{O} 3$ & $108.2(11)$ & $107.8(10)$ & $109.2(11)$ \\
\hline $\mathrm{O} 1-\mathrm{Mo}-\mathrm{O} 1$ & $111.8(18)$ & $107.0(17)$ & $113.3(17)$ \\
\hline $\mathrm{O} 2-\mathrm{Mo}-\mathrm{O} 3$ & $107.5(11)$ & $106(2)$ & $107.9(10)$ \\
\hline \multicolumn{4}{|l|}{ Mo $b$ tetrahedron } \\
\hline $\mathrm{Mo}-\mathrm{O} 1 \times 2$ & $1.77(6)$ & $1.72(9)$ & $1.85(3)$ \\
\hline $\mathrm{Mo}-\mathrm{O} 2$ & $1.72(16)$ & $1.72(13)$ & $1.72(11)$ \\
\hline $\mathrm{Mo}-\mathrm{O} 3$ & $1.68(11)$ & $1.63(16)$ & $1.76(8)$ \\
\hline $\mathrm{O} 1-\mathrm{Mo} b-\mathrm{O} 2$ & $111(4)$ & $109(4)$ & $111(5)$ \\
\hline $\mathrm{O} 1-\mathrm{Mo} b-\mathrm{O} 3$ & $109(5)$ & $108(6)$ & $110(5)$ \\
\hline $\mathrm{O} 1-\mathrm{Mo} b-\mathrm{O} 1$ & $112(8)$ & $111(9)$ & $113(6)$ \\
\hline $\mathrm{O} 2-\mathrm{Mo} b-\mathrm{O} 3$ & $106(8)$ & $105(6)$ & $106(10)$ \\
\hline
\end{tabular}

position $M=\left(\mathrm{K}_{0.5} \mathrm{Yb}_{0.5}\right)$. The $\mathrm{Yb}-\mathrm{O}$ distances corresponding to the mixed $t$ range $\left(\Delta t_{\mathrm{Yb}}=0.25 \pm 0.0062\right.$ and $0.75 \pm 0.0062$, Fig. 3) have unusually larger values, $2.4-2.68 \AA$, in comparison to the remaining part of the $\mathrm{Yb} t$ range, where the distances vary between 2.17 and $2.6 \AA$. Both $\Delta t_{\mathrm{Yb}}$ ranges are associated with the $\left(\mathrm{K}_{0.5} \mathrm{Yb}_{0.5}\right)$ mixed composition (Fig. 3). In other words, approximately $2.5 \%$ of the $M$ position have a mixed composition $\left(\mathrm{K}_{0.5}, \mathrm{Yb}_{0.5}\right)$. Both $\mathrm{Yb}$ and $\left(\mathrm{K}_{0.5} \mathrm{Yb}_{0.5}\right)$ positions are characterized by the coordination number $\mathrm{CN}=6$. 


\section{research papers}

\subsection{Description of the incommensurate $\beta-\mathrm{K}_{5} \mathrm{Yb}\left(\mathrm{MoO}_{4}\right)_{4}$ structure}

Fragments of the incommensurately modulated $\beta$ $\mathrm{K}_{5} \mathrm{Yb}\left(\mathrm{MoO}_{4}\right)_{4}$ structure related to the trigonal palmierite structure type (Fig. 1 and 2) are shown in Figs. 4 and 5.

Similar to the trigonal $\alpha$ phase (Fig. $1 a$ ), the $\beta$ phase can be described as a series of $L$ layers stacked along the $\mathbf{c}$ axis (Fig. 4). All $L$ layers in the $\beta$ phase also have identical compositions and topologies (Fig. 5). However, $\beta$ - $\mathrm{K}_{5} \mathrm{Yb}\left(\mathrm{MoO}_{4}\right)_{4}$ exhibits some characteristic features, which are related to two possible occupations of the $M$ position ( $\mathrm{K} 1$ or $\mathrm{Yb}$ ). The distribution of
$\mathrm{Yb}$ and $\mathrm{K} 1$ in the structure is periodic along the superspace direction $\mathbf{A}_{2}$, but aperiodic along the $\mathbf{b}$ direction. Note that the two vectors are related by the expression $\mathbf{A}_{2}=\mathbf{b}-(\mathbf{q} \cdot \mathbf{b}) \mathbf{A}_{4}$ with $\left\|\mathbf{A}_{4}\right\|=1$ (Fig. 6). Thus, the $\beta-\mathrm{K}_{5} \mathrm{Yb}\left(\mathrm{MoO}_{4}\right)_{4}$ structure can be described by an aperiodic (but not arbitrarily) distribution of $M$ clusters along the $\mathbf{b}$ axis (Fig. 5).

\section{Discussion}

\subsection{Complex cation-anion and cation-cation interactions}

The basis of our analysis of the atomic interactions is the variation of interatomic distances along the internal coordinate $t$. If an independent variation is observed (i.e. not related by any symmetry operation), the strength of the interaction is inversely related to the magnitude of the variation.

The $\mathrm{Mo}-\mathrm{O}$ distances and angles are the most stable entities in this structure (Table 3). As expected, the occupancy of the $M$ position is correlated to the difference between the $\mathrm{Yb}-\mathrm{O}$ and $\mathrm{K} 1-\mathrm{O}$ distances (Fig. 3). In spite of a stable coordination number, $\mathrm{CN}=$ 6 , the $\mathrm{Yb}-\mathrm{O}$ distances exhibit some large fluctuations with a maximal value of $\Delta d_{\max }=0.5 \AA$ for a single $\mathrm{Yb}-\mathrm{O}$ distance. The $\mathrm{CN}$ of $\mathrm{K} 1$ is 8,10 or 12 depending on the value of the internal coordinate $t$. The $\mathrm{K} 1-\mathrm{O}$ distances vary between 2.46 and $3.88 \AA$ with $\Delta d_{\max }=$ $1.08 \AA$. For $\mathrm{CN}=10$, the $\mathrm{K} 2-\mathrm{O}$ distances vary more (from 2.49 to $3.98 \AA$ with $\Delta d_{\max }=1.37 \AA$ ) than the $\mathrm{K} 1-\mathrm{O}$ distances. The variability of the distances related to the first coordination sphere of $\mathrm{Yb}$ and $\mathrm{K}$ atoms points to an additional type of interaction. This is related to the cation-cation interactions in the second coordination sphere. A comparison of the $M-\mathrm{O}$ and $M-$ cation distances (Fig. 3) reveals that a larger number of shorter $M-\mathrm{O}$ distances are correlated to an increase in longer $M$-cation distances.

As seen in Figs. 3-5, the ordering of $\mathrm{K} 1$ and $\mathrm{Yb}$ in the $M$ position induces a rotation and displacement of the $\mathrm{MoO}_{4}$ tetrahedra in order to form $\mathrm{YbO}_{6}$ octahedra. However, the Mo atoms at the centres of these units are stable,

Interatomic distances in the second (upper part) and first coordination spheres (lower part) for the $M$ atoms as a function of the internal coordinate $t$. In the upper part, only the $M-\mathrm{K} 2$ curves are indicated, with the remaining curves corresponding to $M$-Mo distances. The average distances are represented by dotted lines. Owing to the symmetry of the $M$ position, every curve indicates two symmetrically equivalent distances. The $t$ ranges related to $M=\mathrm{K} 1$ and $M=\mathrm{Yb}$ are separated by solid vertical lines. The two $t$ ranges located between the solid and dashed lines are associated with the mixed $M=\left[\mathrm{K}_{0.5} \mathrm{Yb}_{0.5}\right]$ composition. The vertical dotted lines separating the $t$ ranges relate to different crenel functions. The corresponding shapes of the $\left[M \mathrm{O}_{n}\right]$ and $\left[M \mathrm{Mo}_{6} \mathrm{~K}_{2}\right]$ polyhedra are also indicated. 


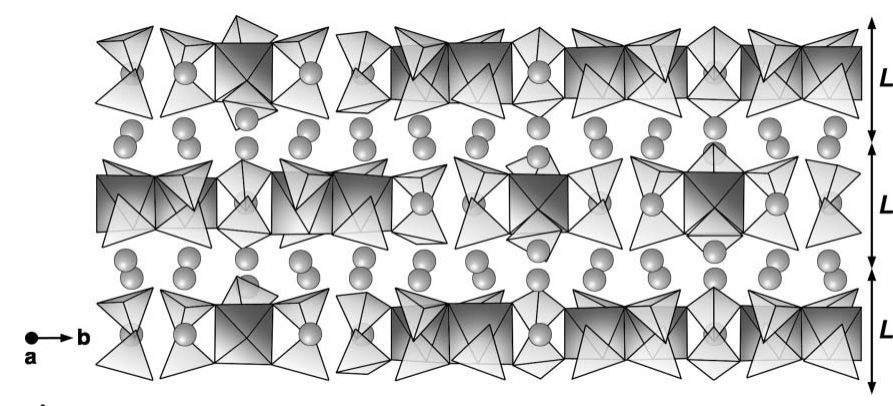

Figure 4

A fragment of the $\beta-\mathrm{K}_{5} \mathrm{Yb}\left(\mathrm{MoO}_{4}\right)_{4}$ structure projection along the $a$ axis. The $\mathrm{YbO}_{6}$ octahedra (dark grey) and $\mathrm{MoO}_{4}$ tetrahedra (light grey) are indicated along with the circles for the $\mathrm{K}$ atoms. The distribution of $\mathrm{K}$ and $\mathrm{Yb}$ is aperiodic along the $b$ axis.

thus keeping the $\left[\mathrm{MMo}_{6} \mathrm{~K}_{22}\right]$ cubic cluster unchanged. Since the $\mathrm{Yb}-\mathrm{Mo}$ distances remain in the range 3.66-3.80 $\mathrm{A}$, the increase of the $\mathrm{Yb}-\mathrm{O}$ distances in the octahedra is mainly balanced by a shortening of the $\mathrm{Yb}-\mathrm{K} 2 a$ distances from 3.92 to $3.82 \AA$ in the $\mathrm{Yb}$ clusters (Fig. 3). Beside the $\mathrm{MoO}_{4}$ tetrahedra, the $\mathrm{Yb}$ cluster has the least variable interactions $\left(\Delta d_{\max }\right.$ $=0.15 \AA$ ).

The K1 clusters are less stable than the Yb cluster owing to the various coordination numbers in the first coordination sphere (Fig. 3). The shortest average K1-Mo distances in the second coordination sphere are correlated with the longest average $\mathrm{K} 1-\mathrm{O}$ distance in the first coordination sphere. The highest coordination number $(\mathrm{CN}=12)$ of the $\mathrm{K} 1-\mathrm{O}$ interactions induces a transformation of the cubic $\mathrm{K} 1$ cluster into a [K1 $\left.\mathrm{Mo}_{6}\right]$ octahedron as a consequence of the elongation of two $\mathrm{K} 2 b$ vertices $(\mathrm{K} 1-\mathrm{K} 2 b>4.38 \AA$, Figs. 3 and 5). The balance between the $\mathrm{K} 1-\mathrm{O}$ and $\mathrm{K} 1-\mathrm{K} 2$ interactions can be directly associated with the close correlation between the K2 and $\mathrm{MoO}_{4}$ crenel functions: in the lower part of Fig. 3 we observe that each $\mathrm{K} 1-\mathrm{O}$ coordination number is associated with a specific configuration of tilts and shifts of the $\mathrm{MoO}_{4}$ tetrahedra; we also observe that the $\mathrm{K} 1-\mathrm{K} 2$ interactions vary for each coordination number. It is important to note that the third coordination sphere of K1 uniquely determines the $\mathrm{CN}$ in the first coordination sphere (Fig. 5): six $\mathrm{Yb}$ clusters surround a $\mathrm{K} 1$ [CN = 12] cluster; four $\mathrm{Yb}$ clusters and two $\mathrm{K} 1$ clusters surround a $\mathrm{K} 1[\mathrm{CN}=$ 10] cluster; three $\mathrm{Yb}$ clusters and three $\mathrm{K} 1$ clusters surround a $\mathrm{K} 1$ $[\mathrm{CN}=8]$ cluster.

The behaviour of the $\mathrm{K} 2 a$ atom can be better expressed by its contribution to the stabilization of the $M$ cluster $(3.83<\mathrm{K} 2 a-M<$ $4.02 \AA$ with $\Delta d_{\max }=0.1 \AA$, Fig. 3) than by its role as the centre of the $\mathrm{K} 2 a \mathrm{O}_{10}$ polyhedron $(2.49<\mathrm{K} 2 a-$ $\mathrm{O}<3.7 \AA$ with $\Delta d_{\max }=0.9 \AA$ ). This contrasts with the $\mathrm{K} 2 b$ atom, which is not associated with an $M$ cluster and which consequently exhibits a smaller variation of the $\mathrm{K}_{2} b \mathrm{O}_{10}$ polyhedron $(2.75<\mathrm{K} 2 b-\mathrm{O}<$ $3.55 \AA$ and $\Delta d_{\max }=0.3 \AA$ ). Three additional and relatively short K2-K2 distances (3.42-3.92 A, and $\Delta d_{\max }=0.3 \AA$ ) between nonshared vertices of the $\left[M \mathrm{Mo}_{6} \mathrm{~K}_{22}\right]$ cubic cluster should also be mentioned. These paired interactions contribute to the linking of two neighbouring $L$ layers (Figs. 1 and 2). Here also the largest $\mathrm{K} 2 b-$ $\mathrm{K} 2$ distance, $3.8 \AA$, is smaller by $0.12 \AA$ compared with the largest $\mathrm{K} 2 a-\mathrm{K} 2$ distance, $3.92 \AA$, which is
Figure 5

Fragment of a single $L$ layer in $\beta$ - $\mathrm{K}_{5} \mathrm{Yb}\left(\mathrm{MoO}_{4}\right)_{4}$. The polyhedra of $(a)$ the first and $(b)$ the second coordination spheres are shown for $M=\mathrm{Yb}$ and $M=\mathrm{K} 1$ atoms. The K2 atoms located on both sides of the $M$ polyhedra along $\mathbf{c}$ are missing in $(a)$. The $M=\mathrm{Yb}$ and $M=\mathrm{K} 1$ clusters are shown in detail in Figs. 2 and 3 . The numbers indicate the $\mathrm{CN}$ of $\mathrm{K} 1$ atoms in their first coordination sphere. 
a consequence of the fact that $\mathrm{K} 2 b$ does not contribute to the formation of $M$ clusters.

From the present analysis we can draw the following conclusions:

(i) Besides the $\mathrm{MoO}_{4}$ tetrahedra, the cubic $M$ clusters, $\left[M \mathrm{Mo}_{6} \mathrm{~K}_{22}\right]$, are the most stable building units in the incommensurately modulated structure $\beta-\mathrm{K}_{5} \mathrm{Yb}\left(\mathrm{MoO}_{4}\right)_{4}$ of the palmierite family. This observation justifies the interpretation of this structure in terms of building units of $M$ clusters (Fig. 2).

(ii) The atomic interactions of the first (cation $\mathrm{O}$ atoms) and second ( $M$ cluster) coordination sphere are correlated.

(iii) The shape of the first coordination sphere of $M=\mathrm{K} 1$ atoms is uniquely determined by the third coordination sphere, i.e. it is directly related to the nature of the surrounding $M$ clusters (Fig. $5 b$ ). In order words, the distribution of $\mathrm{K} 1$ and $\mathrm{Yb}$ atoms among the $M$ clusters drives the tilts and shifts of the $\mathrm{MoO}_{4}$ tetrahedra.

\subsection{Driving forces of the modulation}

The incommensurately modulated structure is associated with the distribution of $\mathrm{K}$ and $\mathrm{Yb}$ in the $M$ position along the $b$ axis. Therefore, the primary modulation parameter is the occupation of the $M$ position, which is best described by complementary crenel functions for the $\mathrm{K}$ and $\mathrm{Yb}$ atoms. The distribution of the $\mathrm{K} 1$ and $\mathrm{Yb}$ clusters in the $L$ layer determines the third coordination sphere of every $\mathrm{K} 1$ and $\mathrm{Yb}$ atom. The third coordination sphere of every $\mathrm{K} 1$ and $\mathrm{Yb}$ atom in

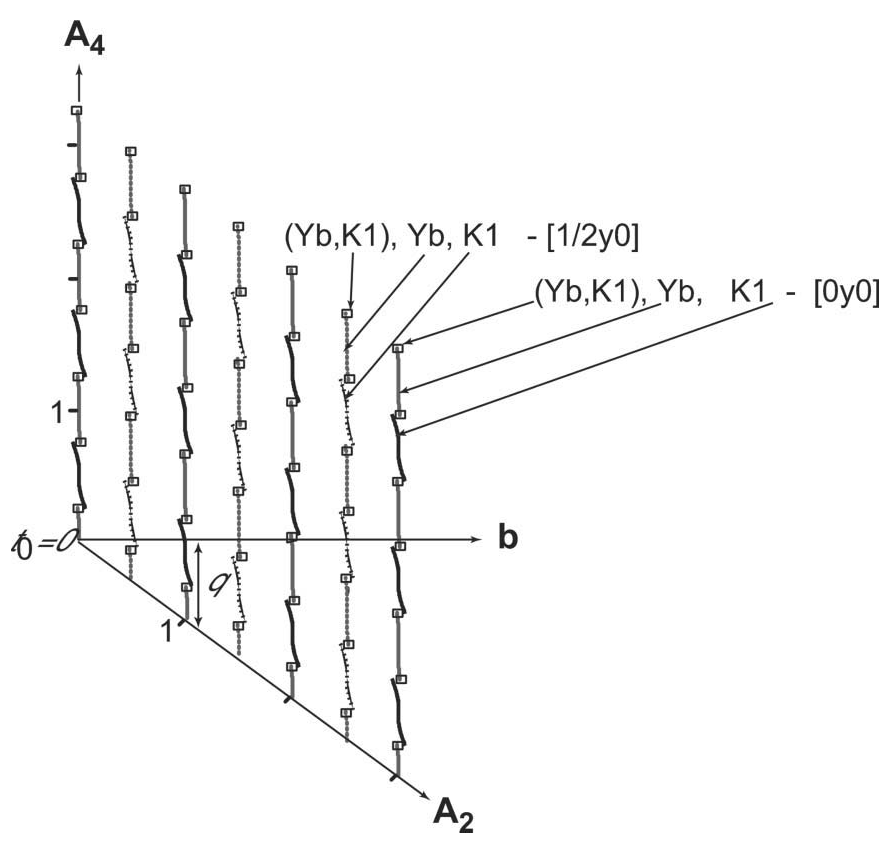

Figure 6

Occupational modulation of the $M$ position in the incommensurate structure $\beta-\mathrm{K}_{5} \mathrm{Yb}\left(\mathrm{MoO}_{4}\right)_{4}$, section $x_{2} x_{4}\left[x_{3}=0 ; x_{1}=0\right.$ and $\left.\frac{1}{2}\right]$. Along $\mathbf{b}$, the aperiodic sequence of $\mathrm{K} 1$ and $\mathrm{Yb}$ defines their distribution in the $L$ layer (see the text, and Figs. 4 and 5): solid lines refer to $x_{1}=0$, whereas dashed lines refer to $x_{1}=\frac{1}{2}$. The terms of the mixed $(\mathrm{Yb}, \mathrm{K})$ position are also indicated. turn determines their first coordination sphere, i.e. the shift and tilt of the $\mathrm{MoO}_{4}$ tetrahedra in order to form the bonds in the $M \mathrm{O}_{n}$ polyhedron (Fig. 5). Since the distribution of the $\mathrm{K} 1$ and $\mathrm{Yb}$ clusters is aperiodic along the modulation vector $\mathbf{q}$, the tilt and shift of $\mathrm{MoO}_{4}$ tetrahedra are modulated according to this distribution. The distances in the $M \mathrm{O}_{n}$ polyhedra (first coordination sphere) and in the $M$ clusters (second coordination sphere) are correlated, thus leading to the modulation of the $\mathrm{K} 2$ atoms.

\section{Conclusions}

The second coordination sphere plays an important role in the formation of incommensurately modulated structures. This was predicted theoretically (Selke \& Fischer, 1979; Janssen \& Tjon, 1981; Bak, 1982; Parlinski \& Chapuis, 1993) and the present study of $\beta-\mathrm{K}_{5} \mathrm{Yb}\left(\mathrm{MoO}_{4}\right)_{4}$ is an additional example confirming this prediction. In the incommensurate structures of $\mathrm{Na}_{2} \mathrm{CO}_{3}$ and $\mathrm{K}_{3} \mathrm{In}\left(\mathrm{PO}_{4}\right)_{2}$ (Chapuis \& Arakcheeva, 2004; Arakcheeva et al., 2003), and $\mathrm{K}_{13} \mathrm{P}_{4} \mathrm{~W}_{8} \mathrm{O}_{32}$ (Dusek et al., 2002) the origin of the modulation was also directly associated with interactions in the second coordination sphere, whereas in the palmierite-like structure $\beta-\mathrm{K}_{5} \mathrm{Yb}\left(\mathrm{MoO}_{4}\right)_{4}$, these interactions affect the bonds between neighbouring atoms. The $\beta$ $\mathrm{K}_{5} \mathrm{Yb}\left(\mathrm{MoO}_{4}\right)_{4}$ structure thus illustrates the complementary character of the interactions between the first and second coordination spheres. Moreover, this structure indicates that the third coordination sphere also plays an important role in the formation of modulated structures.

The contribution of the Swiss National Science foundation, grant No. 20-105325, is gratefully acknowledged. This work was also supported by the Grant Agency of the Czech Republic, grant 202/03/0430

\section{References}

Arakcheeva, A., Chapuis, G., Petricek, V., Dusek, M. \& Schönleber, A. (2003). Acta Cryst. B59, 17-27.

Bak, P. (1982). Rep. Prog. Phys. 45, 587-629.

Becker, P. J. \& Coppens, P. (1974). Acta Cryst. A30, 129-153.

Chapuis, G. \& Arakcheeva, A. (2004). Z. Kristallogr. 219, 730-736.

Dusek, M., Ludecke, J. \& van Smaalen, S. (2002). J. Mater. Chem. 12, 1408-1414.

Janssen, T. \& Tjon, J. A. (1981). Phys. Rev. B, 24, 2245-2248.

Morozov, V. A., Lazoryak, B. I., Lebedev, O. I., Amelinckx, S. \& Van Tendeloo, G. (2003). J. Solid State Chem. 176, 76-87.

Oxford Diffraction Ltd (2001). CrysAlis Software System. Version 1.166. Oxford Diffraction Ltd, UK.

Petricek, V., Dusek, M. \& Palatinus, L. (2000). JANA2000. Institute of Physics, Praha, Czech Republic.

Parlinski, K. \& Chapuis, G. (1993). Phys. Rev. B, 47, 13983-13991.

Schönleber, A., Meyer, M. \& Chapuis, G. (2001). J. Appl. Cryst. 34, 777-779.

Selke, W. \& Fischer, M. E. (1979). Phys. Rev. B, 20, 257-265. 